\title{
Good Intentions, Optimistic Self-Predictions, and Missed Opportunities
}

Social Psychological and

Personality Science

2(I) $90-96$

(C) The Author(s) 201I

Reprints and permission:

sagepub.com/journalsPermissions.nav DOI: I0.1 I77/|9485506/0375722

http://spps.sagepub.com

@SAGE

\author{
Derek J. Koehler', Rebecca J. White ${ }^{2}$, and Leslie K. John ${ }^{3}$
}

\begin{abstract}
Self-predictions are highly sensitive to current intentions but often largely insensitive to factors influencing the readiness with which those intentions are translated into future behavior. When such factors are under a person's control, they could be used to increase the probability that desired future behavior will be undertaken, but they will be underused if self-predictions underestimate their impact. This hypothesis was borne out in two experiments involving working students attempting to achieve a savings goal: They strongly intended to save, made overly optimistic self-predictions even when it was costly to do so, and were willing to pay very little for a service that could help them save more because they did not anticipate its impact on their future behavior. By contrast, students who were informed of the service's actual impact were willing to pay more for it, and students did not underestimate the impact of the service on fellow students.
\end{abstract}

\section{Keywords}

optimism, subjective probability, goals

People are often overly optimistic that they will engage in future behaviors, such as exercising every morning, that satisfy goals that they hold, such as getting into better physical shape (e.g., Buehler, Griffin, \& Ross, 1994; Epley \& Dunning, 2000). Optimistic bias in self-predictions can be costly when decisions depend on their accuracy, such as when an individual buys an expensive piece of home exercise equipment based on an overly optimistic prediction of how often he or she will use it.

Koehler and Poon (2006) suggest that people's selfpredictions typically start with, and consequently overweight, the strength of their intentions regarding the target behavior at the time of prediction. The usefulness of current intentions as a predictor of future behavior has been demonstrated in extensive research based on the theory of planned behavior (e.g., Ajzen, 1991; Ajzen \& Madden, 1986). Generally, the stronger the current intention, the more likely it is that the behavior will be carried out in the future. But according to Koehler and Poon's analysis, self-predictions based on strong intentions will be overly optimistic when, as is typically the case (Armitage \& Conner, 2001; Webb \& Sheeran, 2006), those intentions have only moderate validity as a predictor of future behavior. This analysis implies that factors that influence intentions will tend to be overweighted in self-predictions.

Other factors may affect behavior not by influencing intentions directly but rather by influencing the readiness with which those intentions can be translated into action. For example, placing home exercise equipment in an inviting location, where a nice view, music, or other distractions are available, may help a person use it as regularly as intended. These influences fall into a category that Lewin (1951) described as "channel" factors (see Ross \& Nisbett, 1991). Because such factors influence the "translatability" of intentions into action but not necessarily the strength of those intentions, however, self-predictions will be insufficiently sensitive to their impact if such predictions are anchored on an initial evaluation of intention strength.

In the present research, we identify and distinguish two types of costs associated with self-predictions' insensitivity to factors influencing the translatability of intentions into behavior. First, many decisions are contingent on self-predictions, and therefore regrettable decisions will be made (e.g., paying too much for exercise equipment that is not used) when selfpredictions overweight current intentions and underweight how readily those intentions can be translated into action. Experiment 1 provides a demonstration that participants make systematically costly decisions that are associated with biased self-predictions. Second, although some decisions can have

\footnotetext{
'University of Waterloo, Ontario, Canada

${ }^{2}$ University of Chicago, IL, USA

${ }^{3}$ Carnegie Mellon University, Pittsburgh, PA, USA
}

Corresponding Author:

Derek J. Koehler, University of Waterloo, Department of Psychology, Waterloo, Ontario N2L 3GI, Canada

Email: dkoehler@uwaterloo.ca 
outcomes that are contingent on the future behavior being predicted, other decisions can have outcomes that directly affect the probability of the future behavior itself. When factors that influence the translatability of current intentions into future behavior are under the individual's control, insensitivity to their impact can lead the individual to miss opportunities to use them as a means of making goal achievement more likely (e.g., failing to move home exercise equipment to a more inviting location). Experiment 2 provides a demonstration of such underutilization.

We test these ideas in the context of personal financial savings, which is typically tied to strong intentions and thus is expected to be associated with optimistic self-predictions. For example, two thirds of surveyed employees at a large U.S. corporation indicated they were not saving as much for retirement as they should, and fully one third of this group indicated an intention to increase their $401(\mathrm{k})$ contribution rate in the next few months, but only $14 \%$ of those with good intentions actually did so (Choi, Laibson, Madrian, \& Metrick, 2006). Indeed, insufficient savings for retirement (e.g., Moore \& Mitchell, 1997) and for unexpected life events (e.g., Chang \& Huston, 1995) is seen as a looming crisis in North America. There are a wide variety of financial mechanisms available that could potentially help people to save more (e.g., Thaler \& Benartzi, 2004), such as automatic monthly transfers from a bank account to a pension plan. If the impact of such mechanisms is underestimated in self-predictions of future savings behavior, however, they will be underutilized.

Our experiments involved university students in a cooperative education program. These students alternate work and study terms, and most attempt to save a substantial portion of their income during their work term for use during the subsequent study term. Students were contacted during the first week of a work term and asked to set a savings goal for the term and then to estimate the probability that they would achieve their goal. We refer to this probability estimate as a selfprediction. The students were contacted again at the end of the term and asked if they had achieved their savings goal. This setting serves as a useful microcosm for investigating larger-scale savings behavior, with the practical benefit of offering a welldefined, relatively short-term savings outcome as the target behavior for self-predictions.

In our experiments, some of the students were asked to report their progress toward their savings goal every other week during the work term. Self-reporting (i.e., explicit self-monitoring) of goal-relevant behaviors and outcomes has been found to increase the likelihood of eventual goal achievement (e.g., Morgan, 1987; Sagotsky, Patterson, \& Lepper, 1978; Zimmerman \& Kitsantas, 1997). Thus, this experimental manipulation was expected to increase the likelihood that the students would achieve their savings goals (i.e., enhance the "translatability" of their good intentions into future behavior) relative to a control group that did not regularly evaluate and report their progress. The students knew whether they would or would not be required to report their savings progress through the term at the time they made their self-predictions. But because self-predictions are postulated to be based on current intentions, and because we did not expect that strength of intentions to save would be influenced by the progress report manipulation, we hypothesized that the influence of the manipulation on actual savings behavior would be underestimated in selfpredictions.

In Experiment 1, specifically, we hypothesized that participants would exhibit insensitivity to the impact of the manipulation not only in direct probability judgments but also in prices set on a "savings bonus" opportunity despite having a financial incentive to set their prices in an unbiased manner. In Experiment 2, we gave students the opportunity to subscribe, at some cost, to a service that used progress reports as a means of helping them to achieve their savings goals. We hypothesized that, because of insensitivity of self-predictions to the service's impact, students would undervalue the service and thereby miss an opportunity to make achieving their savings goal more likely.

\section{Experiment I}

\section{Method}

Approximately 4,000 University of Waterloo cooperative education students were invited via email at the beginning of their work term to participate in a web-based study in which they could earn up to $\$ 10$ and could win gift certificates to a local restaurant. Enrollment was limited to the first 400 respondents.

Participants first completed a budgeting worksheet designed to aid them in determining a savings goal that they would like to reach by the end of the work term. To help participants set a realistic goal, the worksheet provided an estimate of their aftertax net income for the term and also encouraged them to consider likely expenses, before asking them to enter their savings goal either as an absolute dollar value or as a percentage of net income.

Those participants assigned to the progress-report condition were told that every other week during the work term, they would be emailed a link to a web page where they would be asked to report their progress toward their savings goal. Participants assigned to the control condition were not informed of nor asked to complete any progress reports.

Participants next gave an intention strength rating ("Right now, as I think about it, I fully intend to reach my savings goal by the end of this work term") on a scale from 1 (absolutely no intention) to 7 (very strong intention) and estimated the probability of actually achieving their savings goals on a scale from $0 \%$ (certainly will not) to $100 \%$ (certainly will) in $10 \%$ increments.

The participants were then presented with a pricing decision that could be costly if based on inaccurate self predictions. Participants were given a choice between receiving a "savings bonus" that would pay them $\$ 10$ if they achieved their savings goal by the end of the term and a guaranteed amount $X<\$ 10$ that they would receive at the end of the term regardless of whether they achieved their savings goal. Participants were told that the value of the guaranteed amount $\mathrm{X}$ would be 
randomly determined at the end of the terms and that they should specify the minimum value of $X$ that they would accept in lieu of the savings bonus "asset." This elicitation method is said to be incentive compatible, as it is designed to be in respondents' best interest to disclose their true reservation price (Becker, DeGroot, \& Marschak, 1964).

The use of this asset-pricing task enables us to quantify the cost of misprediction. All else equal, participants would be expected to set their selling price for the asset based on the perceived probability of achieving the savings goal, and so we can take the price they set as an implied or indirect self-prediction. Assuming risk neutrality, the implied probability of achieving the savings goal is given by the reservation price set by the individual divided by $\$ 10$. The assumption of risk neutrality is validated by supplemental data we collected in which participants priced risky gambles offering varying probabilities of winning $\$ 10$; average prices coincided quite closely with the expected value of the gambles. When we used the prices set on the gambles to accommodate possible risk aversion (or risk seeking) in the asset pricing task, furthermore, we obtained very similar results to those we report here assuming risk neutrality. Note that any tendency toward risk aversion in the pricing task would lead to underestimation of optimistic bias in our analysis.

Every other week during the work term, participants in the progress-report condition were asked to rate their agreement with the statement, "I am on track toward achieving my savings goal by the end of this term," on a 7-point scale and to estimate the percentage of their savings goal that they had saved thus far in the term. Those who completed the progress report were entered into a lottery to win a $\$ 25$ gift certificate to a local restaurant.

At the end of the work term, approximately 15 weeks after the initial session, all participants were recontacted. They were told that they would receive the $\$ 10$ bonus, regardless of whether or not they had achieved their savings goal. This provided an inducement to complete the follow-up session and also avoided any incentive to misreport savings. Participants were also told that all those who completed the follow-up survey would be entered in a lottery for a $\$ 100$ gift certificate to a local restaurant. Respondents were reminded of the savings goal they had set at the beginning of the term and then were asked to report how much they had actually saved over the term, with encouragement to check their bank balance if necessary to provide this value.

\section{Results}

Analyses are limited to the 305 participants who completed the initial and follow-up surveys. Response rates across the seven progress reports ranged from $90 \%$ to $94 \%$. The average number of progress reports completed by an individual participant was $6.3(S D=1.4)$.

The average savings goal $(M=\$ 5,213, S D=\$ 1,959)$ set by participants was quite ambitious, representing approximately two thirds of their expected net income for the term. As anticipated, participants reported strong intentions to reach their savings goal ( $M=6.0, S D=1.2$ on the 7-point scale) . Consistent with their strong intentions, participants' selfpredictions were quite optimistic, setting their mean probability of achieving their savings goals at $82 \%(S D=16 \%)$. In fact, the predictions were overly optimistic in that only $65 \%$ of participants (197 out of 305) reported having achieved their savings goal when contacted at the end of the work term, $t(304)$ $=6.21, p<.001$. The correlation between self-predictions and intention strength $(r=.64)$ was much stronger than that between actual goal achievement and intention strength $(r=$ $.07), t(302)=9.65, p<.001$, consistent with the claim that self-predictions place too much weight on intentions at the time of prediction.

As expected, participants in the progress-report condition (105 out of 151 , or $70 \%$ ) reported a higher rate of savings goal achievement at the end of the term than did those in the control condition ( 92 out of 154, or $60 \%$ ), $p<.05$ by Fisher's exact test. In a logistic regression, the progress-report manipulation emerged as a predictor $\left(B=0.475, S E_{B}=0.244, p=.052\right)$ of savings goal achievement even when self-predictions $(B=$ $\left.1.57, S E_{B}=0.763, p<.05\right)$ were also included in the model, suggesting that the self-predictions were not fully sensitive to the impact of the progress-report manipulation. In fact, selfpredictions ( $M=81 \%$ with progress reports and $83 \%$ without) exhibited no sensitivity to the impact of this factor on behavior.

The mean selling price set on the savings bonus was $\$ 7.87$ $(S D=\$ 2.52)$, which, assuming risk neutrality, implies a perceived probability of $78.7 \%$ of achieving the savings goal. This implied probability is slightly, and significantly, lower than the mean self-predicted probability, $t(304)=2.12, p<.05$. The selling prices were still too optimistic, however, as the actual expected value of the savings bonus given the mean rate of savings goal achievement was only $\$ 6.46$, indicating a "premium" of $\$ 1.41$ or $22 \%$ paid for being overly optimistic, $t(304)=4.80$, $p<.001$. (When limiting the analysis to those in the control condition, in which participants did not have the benefit of higher savings goal achievement because of the progress report requirement, the premium rises to $\$ 1.84$ or $28 \%$.) Selling prices, like the explicit self-predictions, were insensitive to the impact of the progress report manipulation $(M=\$ 7.93$ with progress reports and $\$ 7.81$ without).

In summary, participants had strong intentions to achieve their savings goals and made optimistic predictions that they would do so. The progress report manipulation had no impact on intentions, and as hypothesized, self-predictions were insensitive to this factor even though it had a significant influence on savings behavior. The optimistic bias observed in the self-predicted probability of achieving the savings goal was also observed in selling prices set on the savings bonus. Although it might be argued that participants interpret the self-prediction task (contrary to instructions) as one of simply reporting their intentions rather than giving a realistic prediction, the optimistic bias associated with the selling prices is not subject to this criticism. Self-predictions based on strong intentions are overly optimistic even in a setting in which such optimism carries costs. 


\section{Experiment 2}

An arguably more pernicious cost of optimistic self-predictions is that they may be associated with undervaluation of steps that could be taken to increase the likelihood of the achievement of important goals. To examine this, we offered participants the opportunity to subscribe, at a price, to a service (which included progress reports) that was designed to help them meet their savings goals. If self-predictions overweight current intentions and underweight their translatability into future behavior, the impact of the service - to the extent that it influences the readiness with which savings intentions are translated into action - would be expected to be underestimated. Consequently, participants may not be willing to pay as much as they should to receive it.

Supplementary data were collected to test for undervaluation of the service. A separate group of students was informed of the impact of the service and then asked how much they would be willing to pay for it. Another group was asked to predict the impact of the service on the savings behavior of their fellow students. Because we attribute undervaluation of the service to biases in self-predictions, we hypothesized that students who were informed of the service's actual impact would be willing to pay more for it and that students would not necessarily underestimate the impact of the service on fellow students.

In Experiment 2, the predicted impact of the service is evaluated via a within-subjects comparison, which addresses the possible concern that the observed insensitivity of selfpredictions in Experiment 1 to the impact of the progress report manipulation is limited to subtle between-subject comparisons.

\section{Method}

Students $(N=430)$ were recruited from the cooperative education program and asked to set a savings goal in the same manner as in Experiment 1. Analyses are restricted to the 289 respondents who completed both the initial and follow-up surveys. Prior to making intention strength ratings and selfpredictions, some participants $(n=145)$ were asked to write a few sentences detailing some of the specific ways in which they would benefit from reaching their savings goal, which was expected to strengthen intentions to do so. Other participants ( $n=144)$ were asked to write a few sentences describing their job duties for the term.

All participants were then informed of a service called UW Dollar\$ense that was designed to help them reach their savings goals. One component of this service was the elicitation of regular progress reports in the same manner as Experiment 1; the other component was a newsletter featuring savings tips sent out during the alternating weeks in which progress reports were not elicited. Participants were told that some of them, by random assignment, would have the opportunity to "purchase" the service at a price that would be deducted from their $\$ 8$ study payment (purchase condition). Others, in the nonpurchase condition, would be randomly assigned either to not receive the service or else to receive the service for free. Before learning of the random assignment outcome, all participants were asked to indicate the maximum price they would be willing to pay (from $\$ 0$ to $\$ 8$ ) to receive the service, using the same incentive-compatible elicitation scheme as in Experiment 1. They were told that the price they set would be binding if they were assigned to the purchase condition. A random clearing price (between $\$ 1$ and $\$ 4$ ), set for each participant in the purchase condition, determined whether the participant did or did not receive the service (at the clearing price). Because the price set by participants in the purchase condition helped to determine whether or not they received the service, we included the nonpurchase condition to be able to estimate the impact of the service in the absence of any self-selection effects.

After setting their prices, participants again were asked to estimate the probability of achieving the savings goal, this time assuming that they were to receive the Dollar\$ense service. Participants were then informed whether they would actually receive the service (and, for those who purchased the service, at what price).

Progress reports were elicited every other week from those who received the service as in Experiment 1. All participants were contacted at the end of the term to complete the followup survey, respondents to which would be entered in a lottery for a $\$ 100$ gift certificate to a local restaurant. At this time, participants reported whether or not they had achieved their savings goal. To emphasize the importance of honest reporting, they were told that some participants would be selected at random and asked to provide evidence (e.g., a bank statement) supporting their reported savings.

\section{Results}

Savings goals were virtually identical, both in absolute value and as a proportion of expected net income, to those set in Experiment 1 and did not differ across conditions. Whether participants were assigned to receive the service on the basis of the prices they set (purchase condition) or at random (nonpurchase condition) had no influence on any of the results, and so we collapse across that variable.

Participants again expressed strong intentions $(M=5.5$, $S D=1.4)$ and gave correspondingly optimistic self-predictions ( $M=84 \%, S D=13 \%)$ that they would achieve their savings goals. Actual goal achievement was substantially lower than predicted, with only $62 \%$ (178 out of 289 participants) meeting their savings goals, $t(288)=7.74, p<.001$. The directed writing manipulation had a modest but statistically significant effect on intention strength $(M \mathrm{~s}=5.8$ and 5.2 after writing about savings benefits and job duties, respectively), $t(287)=$ $3.53, p<.01$, that was also reflected in the self-predictions $(M \mathrm{~s}=86 \%$ and $82 \%$, respectively), $t(287)=2.57, p<.05$, but not in actual behavior ( $M \mathrm{~s}=62 \%$ and $61 \%$, respectively), $t(287)=0.16, p=.74$.

A larger proportion $(68 \%, 84$ out of 124) of participants who received the Dollar\$ense service reported achieving their savings goals than did those who did not receive the service $(57 \%, 94$ out of $165 ; p<.05$ by Fisher's exact test). In a logistic 
regression, the Dollar\$ense service emerged as a significant predictor $\left(B=0.494, S E_{B}=0.251, p<.05\right)$ and intention strength only a marginally significant predictor $(B=0.161$, $S E_{B}=0.089, p=.07$ ) of savings goal achievement.

Participants' self-predictions underestimated the impact of the Dollar\$ense service. When asked to give a second selfprediction assuming they were to receive the service, participants increased their probability estimates on average by less than one percentage point, in comparison to the actual difference in probabilities of goal achievement of more than 10 percentage points between service and no-service conditions. The median and modal predicted difference was $0 \%$, and only $7.6 \%$ of participants predicted a difference of greater than 10 percentage points.

We have hypothesized that the focus of self-predictions on strength of current intentions, and the accompanying neglect of the readiness with which those intentions are translated into future behavior, is what produces insensitivity to the impact of factors influencing translatability such as the progress reports included in the Dollar\$ense service. An alternative possibility is that the impact of the service on savings behavior is simply surprising or counterintuitive, and so people inevitably underestimate it. Contrary to this alternative explanation, however are results from an additional group of cooperative education students $(N=46)$ asked to predict the impact of the service on the savings behavior of their fellow students. Before the service was mentioned, these participants estimated that $40 \%$ of cooperative education students in the study would achieve their savings goal; once the service was described, however, they estimated that $57 \%$ of students receiving the service would achieve their savings goal. In contrast to the self-predictions, where the mean and median difference (reflecting the anticipated impact of the service) was $0 \%$, among those making predictions for others the mean difference was $17 \%(S D=15.9 \%$; median difference $=16.5 \%$ ). Apparently, the failure to anticipate the impact of the service on savings behavior is limited to self-predictions, consistent with our general analysis (see Koehler \& Poon, 2006, for a similar result; also see Epley \& Dunning, 2000).

Willingness to pay (WTP; to be deducted from the $\$ 8$ study payment) to subscribe to the service reflected the belief expressed in the self-predictions that it would have little or no impact on savings goal achievement: Modal WTP was \$0, median WTP was $\$ 1$, and mean WTP was $\$ 1.57$. In short, the typical participant was willing to pay only $\$ 1$ for a program that increased the probability of achieving the savings goal (which was more than $\$ 5,000$, on average) by more than 10 percentage points.

Our interpretation is that underestimation of the service's impact led to its undervaluation. Although estimating the actual value of the service is not straightforward, two attempts to do so support the claim that participants should have been willing to pay more for it. First, a regression of WTP on the difference between the initial self-prediction and that assuming subscription to the service (as a measure of expected impact) was conducted, and then the actual difference (impact) was entered into the resulting regression equation to estimate what participants'
WTP for the service would have been had they known its actual impact. Even by this arguably conservative estimate, the service was worth $\$ 2.37$; mean WTP was only two thirds of this value, and $74 \%$ of participants indicated a lower WTP. Second, another separate group of cooperative education students $(N=$ 48) was presented with the actual savings goal achievement rates in Experiment 2, for students who had and for students who had not received the service. This new group of students was then asked to indicate (using the same elicitation method as in Experiment 2) how much of the $\$ 8$ study payment they would be willing to pay to subscribe to the service, if they were to be enrolled in this study during their next work term. Mean WTP when the impact of the service was known was $\$ 4.29$ $(S D=\$ 2.82, M d n=\$ 4.50)$, nearly 3 times the WTP reported in Experiment 2.

In summary, students underestimated the impact and thereby the value of a service designed to help them achieve their savings goals. We suggest that this is because selfpredictions are guided by an evaluation of strength of current intentions, and this evaluation typically neglects factors (such as those included in the savings service) that influence the translatability of intentions into action. Several results from Experiment 2 support this interpretation. First, offering the savings service did not influence intentions to save as expressed at the time of prediction and also did not influence self-predictions, whereas by contrast a directed writing manipulation that did influence intentions to save also influenced self-predictions. Second, in contrast to the self-predictions, predictions of the savings behavior of fellow students - which presumably are less directly guided by one's own intentions to save - are sensitive to the impact of the savings service. Third, supporting the contention that underestimation of its impact is what produced undervaluation of the service, students who were informed of the actual impact of the service on savings behavior placed greater value on it.

\section{General Discussion}

Our results are consistent with the idea that the problem of inadequate personal savings may be at least partly attributable to an optimistic bias in self-predictions arising from overweighting current (good) intentions to save. This bias prevents people from recognizing the value of potentially helpful savings mechanisms because (a) they think the probability of achieving their savings goal is already high and (b) they view savings behavior as determined largely by intentions and hence not readily influenced by mechanisms or factors with effects that are not mediated through an impact on intentions.

One focus in the field of behavioral economics is on the means by which institutions can structure choices presented to individuals that encourage them to act in their own best long-term interests. This work emphasizes the often profound influence of seemingly minor contextual or environmental variables on major financial decisions. Under the philosophy of libertarian paternalism (Thaler \& Sunstein, 2003; also see Camerer, Issacharoff, Loewenstein, O’Donoghue, \& Rabin, 
2003), employers or governments impose mechanisms that encourage individuals to bring their immediate behavior into better line with their long-term goals and aspirations, without removing their freedom of choice. In many situations, though, it is the individual who must actively take steps to put goalfacilitating mechanisms into place (e.g., going to the bank and arranging for monthly transfers to a retirement savings account). In such cases, self-predictions of their impact on future behavior will determine the individual's willingness to take these steps.

Psychologists have identified a variety of strategies that people can use to increase the likelihood that their future behavior will coincide with their intentions. For example, research by Gollwitzer (1999) suggests that people may more readily achieve their goals if they form a specific, situated plan for carrying out future goal-relevant behavior, which could be viewed in the current framework as enhancing the translatability of intentions into action. But people will take such proactive steps only to the extent that they recognize their potential benefits in terms of influencing future behavior.

Contrary to the standard economic assumption that agents know what is good for them and act in their own best longterm interests, failures of planning and of self-control often lead people to fall short of goals grounded in good intentions (e.g., Loewenstein, 1996; Thaler \& Shefrin, 1981). "Sophisticated" agents who anticipate these failures can act in ways to avoid them, but "naïve" agents may be continually surprised by the discrepancy between their intentions and their actions (O’Donoghue \& Rabin, 1999). Misprediction can be costly if the disproportionate focus on good intentions leads people to overlook steps they could take to make their futures brighter.

\section{Acknowledgments}

We are grateful to the students and administration of Co-operative Education and Career Services at the University of Waterloo, with special thanks to Kerry Mahoney, for their assistance with the studies.

\section{Authors' Note}

A portion of this article was presented at the Annual Meeting of the Society for Judgment and Decision Making, Long Beach, California, USA in November 2009.

\section{Declaration of Conflicting Interests}

The authors declared no potential conflicts of interests with respect to the authorship and/or publication of this article.

\section{Financial Disclosure/Funding}

The authors disclosed receipt of the following financial support for the research and/or authorship of this article: Ontario Premier's Research Excellence Award and a grant from the Social Sciences and Humanities Research Council of Canada to the first author.

\section{References}

Ajzen, I. (1991). The theory of planned behavior. Organizational Behavior and Human Decision Processes, 50, 179-211.
Ajzen, I., \& Madden, T. J. (1986). Prediction of goal-directed behavior: Attitudes, intentions, and perceived behavioral control. Journal of Experimental Social Psychology, 22, 453-474.

Armitage, C. J., \& Conner, M. (2001). Efficacy of the theory of planned behaviour: A meta-analytic review. British Journal of Social Psychology, 40, 471-500.

Becker, G., DeGroot, M., \& Marschak, J. (1964). Measuring utility by a single-response sequential method. Behavioral Science, 9, 226-232.

Buehler, R., Griffin, D., \& Ross, M. (1994). Exploring the "planning fallacy": Why people underestimate their task completion times. Journal of Personality and Social Psychology, 67, 366-381.

Camerer, C., Issacharoff, S., Loewenstein, G., O’Donoghue, T., \& Rabin, M. (2003). Regulation for conservatives: Behavioral economics and the case for "asymmetric paternalism." University of Pennsylvania Law Review, 151, 1211-1254.

Chang, Y. R., \& Huston, S. J. (1995). Patterns of adequate household emergency fund holdings. Financial Counseling and Planning, 6, 119-128.

Choi, J. J., Laibson, D., Madrian, B. C., \& Metrick, A. (2006). Saving for retirement on the path of least resistance. In E. McCaffrey \& J. Slemrod (Eds.), Behavioral public finance: Toward a new agenda (pp. 304-351). New York, NY: Russell Sage.

Epley, N., \& Dunning, D. (2000). Feeling "holier than thou": Are self-serving assessments produced by errors in self or social prediction? Journal of Personality and Social Psychology, 79, 861-875.

Gollwitzer, P. M. (1999). Implementation intentions: Strong effects of simple plans. American Psychologist, 54, 493-503.

Koehler, D. J., \& Poon, C. S. K. (2006). Self-predictions overweight strength of current intentions. Journal of Experimental Social Psychology, 42, 517-524.

Lewin, K. (1951). Field theory in social science. New York: Harper and Row.

Loewenstein, G. (1996). Out of control: Visceral influences on behavior. Organizational Behavior and Human Decision Processes, 65 , 272-292.

Moore, J. F., \& Mitchell, O. S. (1997). Projected wealth and savings adequacy in the Health and Retirement Study (NBER Working Paper 6240). Cambridge, MA: National Bureau of Economic Research.

Morgan, M. (1987). Self-monitoring and goal setting in private study. Contemporary Educational Psychology, 12, 1-6.

O’Donoghue, T., \& Rabin, M. (1999). Doing it now or later. American Economic Review, 89, 103-124.

Ross, L., \& Nisbett, R. E. (1991). The person and the situation. New York, NY: McGraw-Hill.

Sagotsky, G., Patterson, C. J., \& Lepper, M. R. (1978). Training children's self-control: A field experiment in self-monitoring and goal-setting in the classroom. Journal of Experimental Child Psychology, 25, 242-253.

Thaler, R. H., \& Benartzi, S. (2004). Save more tomorrow: Using behavioral economics to increase employee savings. Journal of Political Economy, 112(1), S164-S187. 
Thaler, R. H., \& Shefrin, H. M. (1981). An economic theory of selfcontrol. Journal of Political Economy, 89(2), 392-406.

Thaler, R. H., \& Sunstein, C. R. (2003). Libertarian paternalism. American Economic Review, 93, 175-179.

Webb, T. L., \& Sheeran, P. (2006). Does changing behavioral intentions engender behavior change? A meta-analysis of the experimental evidence. Psychological Bulletin, 132, 249-268.

Zimmerman, B. J., \& Kitsantas, A. (1997). Developmental phases in self-regulation: Shifting from process goals to outcome goals. Journal of Educational Psychology, 89, 29-36.

\section{Bios}

Derek J. Koehler is a professor of psychology at the University of Waterloo.

Rebecca J. White is a postdoctoral fellow with the Center for Decision Research at the University of Chicago Booth School of Business.

Leslie K. John is a doctoral candidate in behavioral decision research at Carnegie Mellon University. 